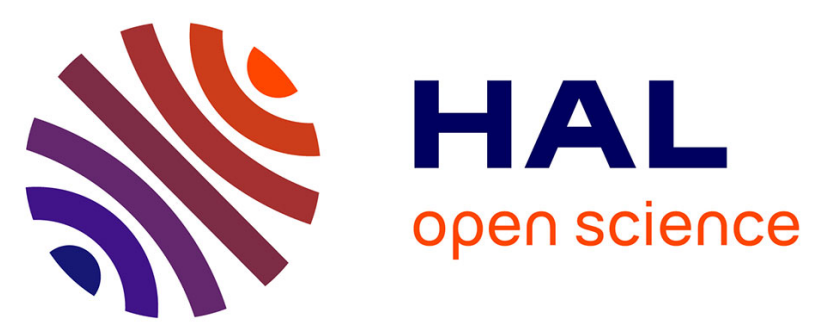

\title{
Structural reliability analysis of deteriorating RC bridges considering spatial variability
}

Trung-Viet Tran, Emilio Bastidas-Arteaga, Franck Schoefs, Stéphanie Bonnet, A. J. O'Connor, Francesca Lanata

\section{- To cite this version:}

Trung-Viet Tran, Emilio Bastidas-Arteaga, Franck Schoefs, Stéphanie Bonnet, A. J. O'Connor, et al.. Structural reliability analysis of deteriorating RC bridges considering spatial variability. 6th International Conference on Bridge Maintenance, Safety and Management, 2012, Stresa, Italy. 10.1201/b12352 . hal-01008969

\section{HAL Id: hal-01008969 \\ https://hal.science/hal-01008969}

Submitted on 9 Oct 2020

HAL is a multi-disciplinary open access archive for the deposit and dissemination of scientific research documents, whether they are published or not. The documents may come from teaching and research institutions in France or abroad, or from public or private research centers.
L'archive ouverte pluridisciplinaire HAL, est destinée au dépôt et à la diffusion de documents scientifiques de niveau recherche, publiés ou non, émanant des établissements d'enseignement et de recherche français ou étrangers, des laboratoires publics ou privés. 


\title{
Structural reliability analysis of deteriorating RC bridges considering spatial variability
}

\author{
T.V. Tran, E. Bastidas-Arteaga, F. Schoefs, S. Bonnet \\ LUNAM Université, Université de Nantes, Institute for Research in Civil and Mechanical Engineering, CNRS \\ UMR 6183, Nantes, France
}

\author{
A.J. O'Connor \\ Trinity College Dublin, Ireland \\ F. Lanata \\ Ecole Supérieure du Bois, Nantes, France
}

\begin{abstract}
This paper proposes an extension of random field theory for modeling spatial variability of deterioration processes, herein, the expansion Karhunen-Loève is used. The studied structure is discretized into several elements and system reliability is used to evaluate the probability of failure. Some considerations for optimal discretization will be also discussed in the paper. The series system methodology will be applied to the reliability analysis of a RC bridge girder placed in a chloride-contaminated environment. The results of this study illustrate the importance of including spatial variability in the problem.
\end{abstract}

\section{INTRODUCCION}

Reinforced concrete (RC) bridges are subjected to actions that could affect its serviceability and safety during their whole life- cycle, e.g., chloride penetration, fatigue, creep, etc... (Bastidas 2010). Under these actions, a structural reliability analysis is essential to anticipate maintenance actions that optimize costs and ensure appropriate levels of serviceability and safety. Nowadays, there are significant advances in probabilistic modeling of these deterioration processes. However, the most part of studies focus the reliability analysis on a single section of the structure (Stewart M.G. et al 2008). Recent works have demonstrated that deterioration processes and loading are highly space-variant (Bastidas et al 2010). Therefore, the consideration of their spatial variability is essential for proper reliability assessment.

Within this context, this paper focus to analyses reliability structural considering the spatial variability of its parameter. The firth, we proposes an extension of random field theory for modeling spatial variability of deterioration processes and an expansion Karhunen-Loève is used (section 3). Thus, the studied structure is discredited into several elements and system reliability is used to evaluate the probability of failure. Herein, we propose method estimation series system reliability (section 4). Some considerations for optimal discretization will be also discussed in the paper. The proposed methodology will be applied to the reliability analysis of a RC bridge girder placed in a chloride-contaminated environment. Data coming from real measurements will be used in both the definition of the variables with larger spatial variability and in their characterization (section 5). The results of this study illustrate the importance of including spatial variability in the problem.

\section{CHLORIDE-INDUCED RC DETERIORATION IN SATURATED ENVIRONMENTS}

Assessment of corrosion effects on RC structures is a difficult task because several deterioration mechanisms interact in the process. The deterioration of $\mathrm{RC}$ induced by corrosion involves the interaction between three mechanisms: ingress of the corroding agent -i.e., chlorides or carbon dioxide, corrosion of reinforcing steel and concrete cracking. The ingress of the corroding agent induces corrosion of the reinforcing bars. The accumulation of corrosion products in the steel/concrete interface generates concrete cracking, which plays an important role in the steel corrosion rate when excessive concrete cracking is reached. Based on the previous considerations, the corrosion process is divided into two stages namely 'corrosion initiation' and 'corrosion propagation'. The following sections describe the physical phenomena as well as outline the adopted models to determine the time to corrosion initiation caused by chloride ingress

\subsection{Chloride ingress mechanism and modeling}

Fick's second law of diffusion is usually used to study the flow of chlorides into concrete (Tuutti, 1982); then for the unidirectional case (flow in $x$ direction): 


$$
\frac{\partial C_{f c}}{\partial t}=D_{c} \frac{\partial^{2} C_{f c}}{\partial x^{2}}
$$

where $C_{f c}$ is the concentration of chlorides dissolved in the pore solution, $t$ is the time and $D_{c}$ is the effective chloride diffusion coefficient. Assuming that concrete is a homogeneous and isotropic material with the following initial conditions: (1) the concentration is zero at $t=0$ and (2) the chloride surface concentration is constant; the free chloride ion concentration $C(x, t)$ at depth $x$ after time $t$ for a semiinfinite medium is:

$$
C(x, t)=C_{s}\left[1-\operatorname{erf}\left(\frac{x}{2 \sqrt{D_{c} t}}\right)\right]
$$

Where $C_{s}$ is chloride surface concentration and $\operatorname{erf}(\cdot)$ is the error function.

The closed-form solution of Fick's diffusion law can be easily used to predict the time to corrosion initiation. However, equation (2) is valid only when $\mathrm{RC}$ structures are saturated and subjected to constant concentration of chlorides on the exposed surfaces. These conditions are rarely present for real structures because concrete is a heterogeneous material that is frequently exposed to time-variant surface chloride concentrations. Besides, this solution does not consider chloride binding capacity, concrete aging and other environmental factors as temperature and humidity (Saetta et al 1993; Bastidas et al 2010, 2011).

The European Union project, (Duracrete, 2000), proposes an expression similar to equation (2) which considers the influence of material properties, environment, concrete aging and concrete curing on the chloride diffusion coefficient:

$$
C(x, t)=C_{s}\left[1-e r f\left(\frac{x}{2 \sqrt{k_{e} k_{t} k_{c} D_{0}\left(\frac{t_{0}}{t}\right)^{n_{D}} t}}\right)\right]
$$

where $k_{e}$ is an environmental factor, $k_{t}$ is a factor which considers the influence of the test method to measure the diffusion coefficient $D_{o}, k_{c}$ is an influence factor for concrete curing, $D_{o}$ is the chloride migration coefficient measured at defined compaction, curing and environmental conditions, $t_{o}$ is the reference period to measure $D_{o}$ and $n_{D}$ is the age factor. The lifetime assessment resulting from this approach is better than the one provided by equation (2) because it accounts for the type of concrete, the $w / c$ ratio, the environmental exposure (submerged, tidal, splash and atmospheric), aging and concrete curing. In addition, the strength of the Duracrete approach lies in considering the randomness related to chloride penetration. Although this method does not take into consideration chloride flow in unsaturated conditions, this model will be used herein to illustrate the phenomena of spatial variability of corroding RC structures.

\subsection{Corrosion initiation}

After corrosion initiation, the diameter reduction of reinforcing bars induced by corrosion can be estimated in terms of a change in the volumetric rate by using Faraday's law:

$$
\begin{aligned}
& d_{u}(t)=d_{0}-0.0232 \int_{t_{i i j}}^{t} i_{c o r r}(t) d t \\
& d_{p}(t)=d_{0}-0.0116 \alpha \int_{t_{\text {ini }}}^{t} i_{\text {corr }}(t) d t
\end{aligned}
$$

where $d_{u}(t)$ and $d_{p}(t)$ are the residual diameters of the reinforcing bar at time $t$ for uniform and pitting corrosion, respectively, $d_{0}(t)$ is the initial diameter of the bar in $\mathrm{mm}, \alpha$ is the ratio between pitting and uniform corrosion depths, and $i_{\text {corr }}(t)$ is the time-variant corrosion rate $\left(\mu \mathrm{A} / \mathrm{cm}^{2}\right)$. Given the complexity of the corrosion process in RC, $i_{\text {corr }}$ depends on many factors such as concrete $\mathrm{pH}$ and availability of oxygen, and water in the corrosion cell. However, for the sake of simplicity, this work assumes that corrosion rate is constant after corrosion initiation.

\section{PROBABILISTIC MODELING}

\subsection{Probability of corrosion initiation}

The time to corrosion initiation, $t_{i n i}$, is defined as the time at which the chloride concentration at the steel reinforcement surface reaches a threshold value, $C_{t h}$. This threshold concentration represents the chloride concentration for which the rust passive layer of steel is destroyed and the corrosion reaction begins. Note that this threshold is sensitive to the chemical characteristics of concrete components: sand, gravel and cement. Therefore, it is assumed herein that $C_{t h}$ is a random variable. The time to corrosion initiation is obtained by evaluating the time-dependent variation of the chloride concentration at the reinforcing steel. This is computed in this work by using equation (3). The cumulative distribution function of the time to corrosion initiation, $F_{\text {tini }}(t)$, is defined as:

$$
F_{t_{\text {ini }}}(t)=P\left(t_{\text {ini }} \leq t\right)=\int_{t_{\text {ini }} \leq t} f(x) \cdot d x
$$

The limit state function that defines corrosion initiation can be written as:

$$
g(\mathbf{X}, t)=C_{t h}(\mathbf{X})-C_{t c}(\mathbf{X}, t)
$$

where $C_{t c}(\mathbf{X}, t)$ is the total concentration of chlorides at the concrete cover depth $c_{t}$ at time $t$. The probability of corrosion initiation, $p_{i n i}$, is obtained by integrating the joint probability function over the failure domain -i.e., equation (5) 


\subsection{Probability of failure}

In this section, we considered the probability of failure of a structure concrete submitted by a loading $S$ and determined by:

$$
P_{f}(\mathbf{X}, t)=P\left(M_{R}(\mathbf{X}, t) \leq M_{S}(\mathbf{X}, t)\right)=\int f(x) d x
$$

where $\mathbf{X}$ is the vector of random variables and $\boldsymbol{f}(\boldsymbol{x})$ is the joint probability density function of $\mathbf{X}, M_{R}$ and $M_{S}$ is a capacity moments and effected moment of the structure at the time $t$. If structural failure is achieved when the crack or pit size reaches a critical value, inducing the cross-section failure, the limit state function becomes:

$$
g\left(A_{s}(a), \mathbf{X}\right)=M_{R}\left(A_{s}(a), \mathbf{X}\right)-M_{s}(\mathbf{X})
$$

where $A_{s}(a)$ is the net steel area, $\mathbf{X}$ is the vector of random variables (i.e., applied load, concrete compressive strength, etc.), $M_{R}\left(A_{s}(a), \mathbf{X}\right)$ is the bending moment capacity and $M_{S}(\mathbf{X})$ is the applied moment at the time $t$. With the $A_{s}(a)$ is determined by (Mark G.S. et all 2008):

$$
A_{s}(a)= \begin{cases}\pi \frac{d_{0}{ }^{2}}{4}-A_{1}-A_{2} & \text { if } p(t) \leq \frac{d_{0}}{\sqrt{2}} \\ A_{2}-A_{1} & \text { if } \frac{d_{0}}{\sqrt{2}} \leq p(t) \leq d_{0} \\ 0 & \text { if } p(t) \geq d_{0}\end{cases}
$$

where

$$
\begin{aligned}
& p(t)=0.0016 . \alpha \cdot i_{\text {cross }} \\
& b=2 . p(t) \sqrt{1-\left(\frac{p(t)}{d_{0}}\right)^{2}}, \\
& A_{1}=0.5\left[\theta_{1}\left(\frac{d_{0}}{2}\right)^{2}-b\left|\frac{d_{0}}{2}-\frac{p(t)^{2}}{d_{0}}\right|\right], \\
& A_{2}=0.5\left[\theta_{2} \cdot p(t)^{2}-b \frac{p(t)^{2}}{d_{0}}\right], \\
& \theta_{1}=2 \cdot \arcsin \left(\frac{b}{d_{0}}\right), \theta_{2}=2 \cdot \arcsin \left(\frac{b}{2 \cdot p(t)}\right),
\end{aligned}
$$

with $d_{0}$ is the initial diameter of the steel bar.

And the equation (7) will be replaced by:

$$
P_{f}=P\left(g\left(A_{s}(a), X\right) \leq 0\right)=\int_{-\infty}^{0} f(x) \cdot d x
$$

\subsection{Spatial variability}

Risk Based Inspection analysis or reliability methods applied to real structures generally assume:

- Either that there is no stochastic field involved in the problem;

- Neither that the location of the most critical defect from reliability point of view is known and the distribution of defects in the neighboring doesn't affect the reliability.

It is well known that the reality is more complex and that we should account for stochastic fields too and non perfect inspections for condition assessment. Then the stochastic field could take several forms more or less complicated:

- The most simple is the stationary stochastic field that is able to model the chloride distribution or other properties in the concrete for instance (Bazant 1991, 2000a, 2000b);

- More sophisticated is the piecewise stationary process that can integrate the variability of the concreating by steps or the corrosion of structures in contiguous but different environments;

- Finally, fully non stationary fields are certainly the most acceptable for a fine representation of properties.

However, except for natural soils, materials used for bridges building are produced following a quality process and control. We can consider that some variation are fair, for instance the spatial change of the mean value. This paper focuses on the first case only.

\subsubsection{Description the spatial variability}

With the hypothesis the stationary stochastic field, the spatial variability will be represented by a trajectory with the distance. In this paper, we used an expansion Karhunen - Loève to represent the spatial variability (Schoefs et all 2011):

$$
Z(x, \theta)=\mu_{Z}+\sigma_{Z} \cdot \sum_{i=1}^{n} \sqrt{\lambda_{i}} \cdot \xi_{i}(\theta) \cdot f_{i}(x)
$$

where, $\mu_{Z}$ is value mean of the field of $\mathrm{Z}, \sigma_{Z}$ is value standard deviation of the field of $\mathrm{Z}, n$ is number of terms in the expansion, $\xi_{I}$ is a set of centered Gaussian random variable reduced, $\lambda_{i}$ and $f_{i}$ are respectively the eigenvalues and eigenfunctions of the covariance function: $\rho(\Delta x)$

To determine the eigenvalues $\lambda_{i}$ and eigenfunctions $f_{i}$, we assume that the field is second order stationary and use the exponential form of correlation function as follows:

$$
\rho(\Delta x)=\exp \left(-\frac{\Delta x}{b}\right) ; \text { with } b>0
$$

And obtain results of eigenvalues and eigenfunctions $\lambda_{\mathrm{i}}$ and $f_{\mathrm{i}}$ : 


$$
\begin{gathered}
\lambda_{i}=\frac{2}{b\left(\frac{1}{b^{2}}+\omega_{i}^{2}\right)} \\
f_{i}(x)=\left\{\begin{array}{l}
\frac{\cos \left(\omega_{i} x\right)}{\sqrt{a+\frac{\sin \left(2 \cdot \omega_{i} \cdot a\right)}{2 \cdot \omega_{i}}}} \text { foriodd } \\
\frac{\sin \left(\omega_{i} x\right)}{\sqrt{a-\frac{\sin \left(2 \cdot \omega_{i} \cdot a\right)}{2 \cdot \omega_{i}}}} \text { forieven }
\end{array}\right.
\end{gathered}
$$

where, $b$ is lounge of correlation and $\omega_{i}$ is solution of transcendental equations:

$$
\left\{\begin{array}{l}
\frac{1}{b}-\omega \tan (\omega \cdot a)=0 \text { for } i \text { odd } \\
\omega-\frac{1}{b} \tan (\omega \cdot a)=0 \text { for } i \text { even }
\end{array}\right.
$$

\subsubsection{Spatial variability of moment capacity.}

In this paper, we consider that concentration chlorides surface $C_{s}$ and the diffusion coefficient $D_{0}$ are a stochastic field and represented by equation 12 . And we obtain the cross-section area of armature by equation 3 and 9 along the RC beam.

The moment capacity of the $\mathrm{RC}$ beam is a function of concrete compressive strength, $f_{c}$ '; effective depth $d$; beam width, $b$; yield stress, $f_{y}$ and crosssectional area of armature $A_{s}(a)$. The moment capacity can closely be approximated as:

$$
M_{R}\left(A_{s}(a), X\right)=A_{s}(a) \cdot f_{y}\left(d-0.5 \frac{A_{s}(a) \cdot f_{y}}{f_{c}^{\prime} b}\right)
$$

for singly reinforced rectangular beams. If the reinforcement layout comprises $n$ reinforcing bars then moment capacity of the beam is a parallel system directly proportional to them sum of yield capacity of each reinforcing bar at time $t$. The moment capacity at any element $j$ at time $t$ is:

$$
M_{R j}(t)=A_{s j}(a, t) \cdot f_{y}(t)\left(d-0.5 \frac{A_{s j}(a, t) \cdot f_{y j}(t)}{f_{c j}^{\prime}(t) \cdot b}\right)
$$

We assume that RC beam comprising $m$ elements, parameter of each element is constant, and the failure mode of the beam will be modeled as a series system. More detailed numerical modeling will lead to more accurate estimates of structural capacities of corroding structures.

\section{STRUCTURAL RELIABILITY ANALYSIS CONSIDERING SPATIAL VARIABILITY OF GEOMETRICAL CHARACTERISTIC}

For the series system, the critical limit state occurs when actual load effects exceed the resistance at any element. In general, if it is assumed that $n$ load events $S$ at times $t$. With a beam comprising $m$ elements, the critical limit state at $i^{\text {th }}$ element is:

$$
G_{i}(\mathbf{X}, t)=M_{R}^{i}(\mathbf{X}, t)-S_{i}(\mathbf{X}, t)
$$

where $M_{R}{ }^{i}$ and $S_{i}$ represents the structural resistance and load effect at the mid-point of $i^{\text {th }}$ element. With the $n$ load event, we obtain $G_{i}$ is a random variable. The cumulative probability of failure of the RC beam at the time $t$ is:

$$
\begin{array}{r}
P_{f S}=1-P\left[G_{1}(X, t)>0 \cap G_{2}(X, t)>0\right. \\
\left.\cap \ldots \cap G_{m}(X, t)>0\right]
\end{array}
$$

And

$$
P_{f S}=1-\Phi_{m}(\vec{\beta},[\rho])
$$

where, $\Phi_{\mathrm{m}}$ is a multinormale distribution, $\beta$ is a vector of reliability indices, $\vec{\beta}=\left\{\beta_{1}, \beta_{2}, \ldots, \beta_{m}\right\}$ with $\beta_{i}$ is a reliability indices of the element $i^{\text {th }}$ and $[\rho]$ is a matrix correlation of the limit state $G$.

If it is assumed that failure elements are independent elements, then the cumulative probability of failure is:

$$
P_{f S} \approx 1-\prod_{i=1}^{m}\left[1-P\left(G_{i}(X, t) \leq 0\right]\right.
$$

To solution equation (21), the FORM method will be used and based on Bi-normal problem. The principal in this method, we use Bi-normal model for the replacement each of two elements by one equivalent element. Figure 1 show detail this method.

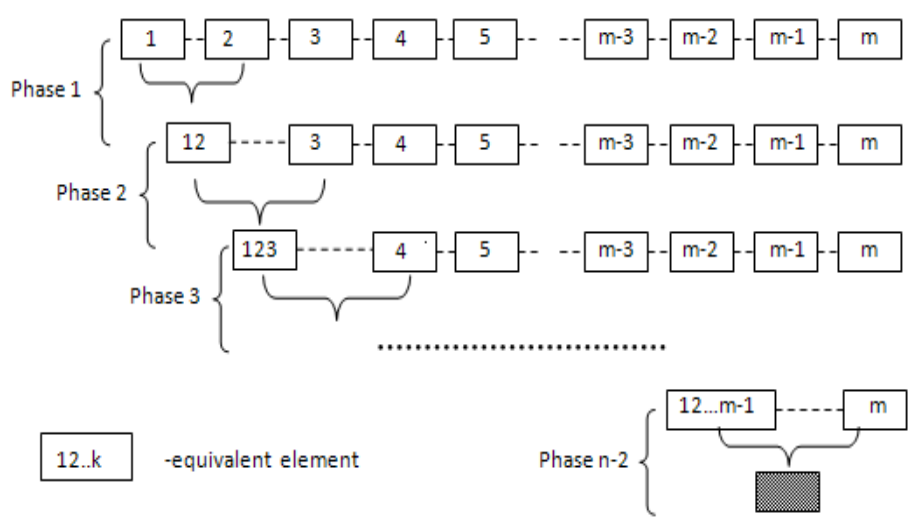

Figure 1: Description evaluation reliability structural in series system method

The firth, we will replace two elements $E_{1}$ and $E_{2}$ by one equivalent element $E_{12}$ with value reliability indices $\beta_{12}$ calculated by:

$$
\beta_{12}=\Phi^{-1}\left[\Phi_{2}\left(\beta_{1}, \beta_{2}, \rho_{12}\right)\right]
$$

And the correlation coefficient entre new equivalent element $E_{12}$ with element $i^{\text {th }}, i=3 \ldots m, \rho_{12 k} \mathrm{ob}-$ tained by (X.-X. Yuan 2006): 


$$
\beta_{12 k}=\frac{\beta_{12}+\rho_{12 k} * A}{\sqrt{1-B^{*} \rho_{12 k}^{2}}}
$$

where, $\beta_{12 k}$ is an equivalent reliability index of $E_{1}$, $E_{2}$ and $E_{k}$ :

$$
\beta_{12 k}=\Phi^{-1}\left(\Phi_{2}\left(\beta_{1 k}, \beta_{2 k}, \rho_{12 \mid k}\right)\right)
$$

where, $\beta_{1 k}, \beta_{2 k}, \rho_{12 l k}$ determinate by:

$$
\begin{aligned}
\beta_{1 k}= & \frac{\beta_{1}+\rho_{1 k} * A}{\sqrt{1-B^{*} \rho_{1 k}^{2}}} \\
\beta_{2 k}= & \frac{\beta_{2}+\rho_{2 k} * A}{\sqrt{1-B^{*} \rho_{2 k}^{2}}} \\
\rho_{12 \mid k} & =\frac{\rho_{12}-\rho_{1 k} * \rho_{2 k} * B}{\sqrt{\left(1-B^{*} \rho_{1 k}^{2}\right) *\left(1-B^{*} \rho_{2 k}^{2}\right)}} \\
A & =\frac{\varphi\left(\beta_{k}\right)}{\Phi\left(\beta_{k}\right)}, \quad B=A *\left(\beta_{k}+A\right)
\end{aligned}
$$

where, $\varphi($.$) noted the PDF of Normal distribution$ standard.

The Monte-Carlo simulation is used herein to evaluate equation (19). At each element $i^{\text {th }}$ at the time $t$, the limit state $S_{i}$ is randomly generated, for this paper, we consider the random Gaussian.

In the numerical example later, we present results for the reliability structural with the correlation between elements.

\section{ASSESSMENT OF THE AUTOCORRELATION PARAMETER}

We assume that the stationary stochastic field can be characterized by an autocorrelation function (ACF).

Table 1 presents the most interesting ACF considered for spatial variability of structures with their parameter, called scale of fluctuation $\theta$. A complete overview of the auto-correlation functions and their application is available in Kenshel (2009).

Two major procedures have been reported in the literature for the estimation of $\theta$ for a spatially variable property from a digitized record of data. In the first procedure, reported by $\mathrm{Li}$ (2004), the Maximum Likelihood Estimate method (MLE) is used in which different values for the model parameter of the proposed ACF model is assumed and the value that maximizes the corresponding MLE is taken as the model parameter. In the second procedure, proposed by Vanmarke (1983), a proposed ACF model (from Table 1) can be adjusted to provide the best fit to the

\begin{tabular}{|c|c|c|c|c|}
\hline & ACF Name & ACF Model & $\begin{array}{c}\text { Scale of } \\
\text { fluctuation } \theta\end{array}$ & Reference \\
\hline 1 & Triangular & $\rho(\tau)= \begin{cases}1-\frac{|\tau|}{a}, & \text { for }|\tau| \leq a \\
0 & \text { for }|\tau|>a\end{cases}$ & $a$ & $\begin{array}{c}\text { (Vanmarcke, } \\
1983)\end{array}$ \\
\hline 2 & Exponential & $\rho(\tau)=\exp \left(-\frac{\tau}{b}\right)$ & $2 b$ & $\begin{array}{c}\text { (Vanmarcke } \\
1983)\end{array}$ \\
\hline 3 & $\begin{array}{l}\text { Second-order } \\
\text { autoregressive }\end{array}$ & $\rho(\tau)=\left[1+\frac{|\tau|}{c}\right] \cdot \exp \left(-\frac{|\tau|}{c}\right)$ & $4 c$ & $\begin{array}{c}\text { (Vanmarcke } \\
1983)\end{array}$ \\
\hline 4 & $\begin{array}{c}\text { Square } \\
\text { exponential } \\
\text { (Gaussian) }\end{array}$ & $\rho(\tau)=\exp \left[-\left(\frac{|\tau|}{d}\right)\right.$ & $\sqrt{\pi} d$ & $\begin{array}{c}\text { (Vanmarcke } \\
1983)\end{array}$ \\
\hline 5 & $\begin{array}{c}\text { Cosine } \\
\text { exponential }\end{array}$ & $\rho(\tau)=\exp \left(-\frac{|\tau|}{e}\right) \cdot \cos \left(\frac{|\tau|}{e}\right)$ & $e$ & $(\mathrm{Kim}, 2005)$ \\
\hline 6 & Sinusoidal & $\rho(\tau)=\frac{\sin \left[-2.2\left(\frac{|\tau|}{f}\right)\right.}{-2.2\left(\frac{|\tau|}{f}\right)}$ & $f$ & $\begin{array}{c}\text { (Gomes and } \\
\text { Awruch, 2002) }\end{array}$ \\
\hline
\end{tabular}
actual sample correlation coefficients $\rho(\Delta x)$ thereby providing estimates of the corresponding model parameter (i.e. a, b, c, d, e or $\mathrm{f}$ in Table 1).
Table 1: Autocorrelation function and corresponding scale parameter $\theta$

In this paper, we select the model 2:

$$
\rho(\Delta x)=\exp \left(-\frac{\Delta x}{b}\right) ; \text { with } b>0
$$

and we use the likelihood estimate for the estimation of $b$.

$$
L=\prod_{i=1}^{k}\left(\frac{1}{\sqrt{2 \pi}} \exp \left(-\frac{v_{i}^{2}}{2}\right)\right)=\left(\frac{1}{\sqrt{2 \pi}}\right)^{k} \exp \left(-\frac{\sum_{i=1}^{k} v_{i}^{2}}{2}\right)
$$

Where $v_{\mathrm{i}}$ is the $i$ th component of the vector of independent standard values obtained from equation:

$$
v=C^{-1}\left(\frac{z-\mu_{Z}}{\sigma_{Z}}\right)
$$

where $\mathbf{z}$ is the vector of realizations of random variable $\mathrm{Z}, \mu_{z}$ and $\sigma_{z}$ respectively the mean value and the standard deviation of the stationary field $Z(x, \theta)$, and $\mathrm{C}$ a lower triangular matrix such that $\mathrm{CC}^{\mathrm{T}}=\rho$ and $\rho$ the autocorrelation matrix.

And, maximize $L$ is equivalent to minimize $L_{l}$ :

$$
L_{1}=\sum_{i=1}^{k} v_{i}^{2}
$$

The data treatment lies on a previous physical analysis to gather similar situations and distinguish others. By considering the second Fick law without initial chloride concentration (i.e. $\mathrm{C}_{0}=0$ ) we consider that:

- the apparent coefficient of diffusion $D_{0}$ depends on the material and the quality of concreting and is assume not to be influence by the exposure;

- the surface chloride content $C_{S}$ depends on the environment and two exposures are considered: for each beam: north and south. 
For the structure considered in section 5, Figure 2 shows the evolution of $L_{l}$ with scale of fluctuation $b$ for $C_{s}$ and two minimum values of this function are obtained for the two exposures: 0.7 and 1.9 respectively for the North and the South exposures.

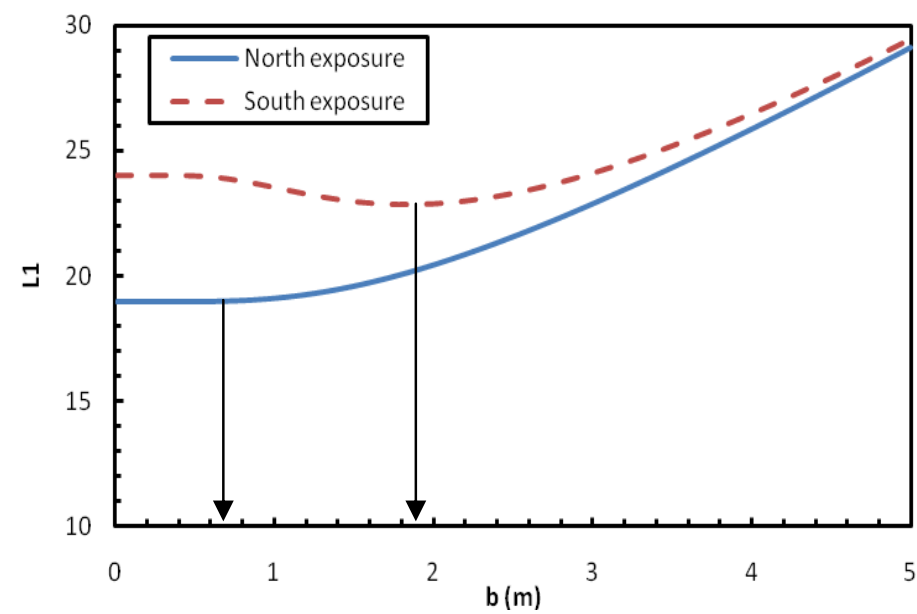

Figure 2: Evolution of function $L_{l}$ with scale of fluctuation $b$ of Cs (Data of Bridge Ferry-Carring, Irlande)

Figure 3 gives the same representation for the scale of fluctuation of $D_{0}$. The minimum values for the two exposures are more close 0.8 and 1.4 respectively for the North and the South exposures. That confirms that the scale of fluctuation should be the same because governs by the material properties and not the exposure. The value 1.1 that corresponds to the merging of data at North and South exposure is selected in the following.

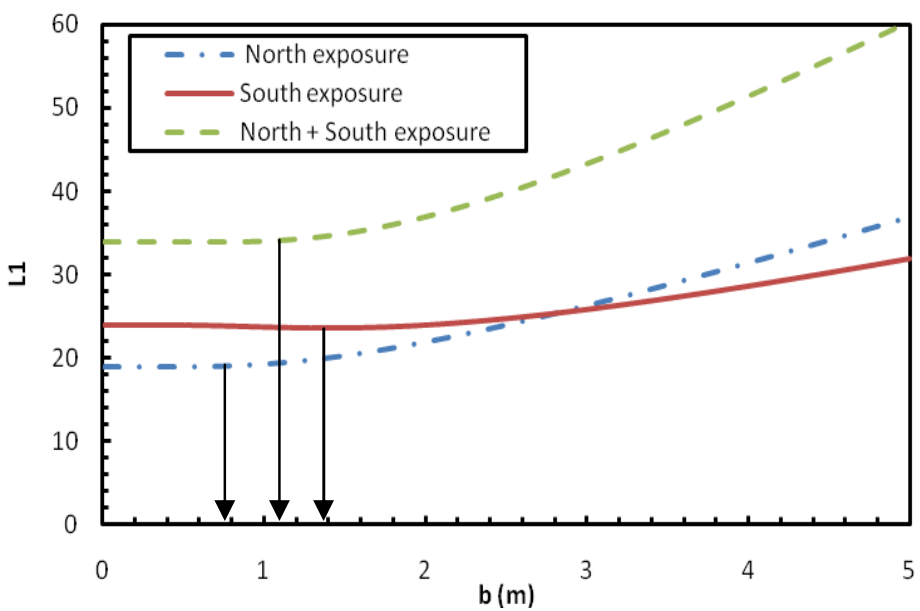

Figure 3: Evolution of function L1 with scale of fluctuation $b$ of D0 (Data of Bridge Ferry-Carring, Irlande)

\section{NUMERICAL EXAMPLE}

\subsection{Problem description}

In this paper, we present the influence of variable spatial of the geometrical characteristics $C_{s}$ and $D_{0}$ in the reliability analyses of RC beam (Figure 4). We consider here three materials:
- Poor: cover $=38 \mathrm{~mm}, \mathrm{w} / \mathrm{c}=0.65$ and $f^{\prime}{ }_{c k}=28 \mathrm{MPa}$.

- Fair: cover $=38 \mathrm{~mm}, \mathrm{w} / \mathrm{c}=0.50$ and $f^{\prime}{ }_{c k}=40 \mathrm{MPa}$.

- Good: cover $=38 \mathrm{~mm}$, w/c $=0.45$ and $f^{\prime}{ }_{c k}=46$ $\mathrm{MPa}$.

With two conditions different of environment: Tidal and Atmospheric. The considered random variables are presented in Table 2.
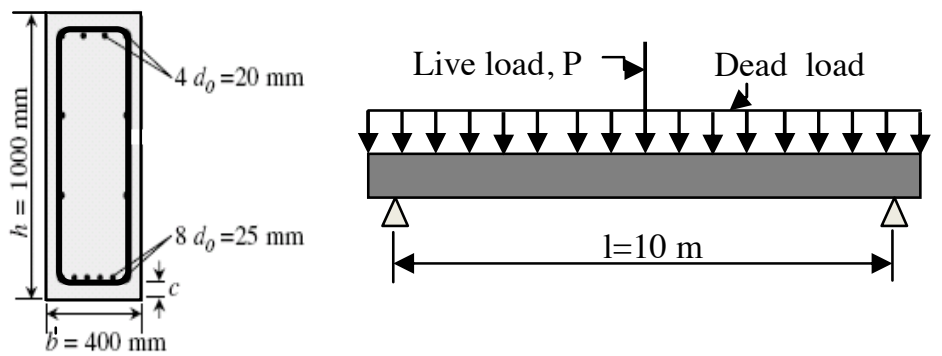

Figure 4: Configuration of the bridge girder

Table 2: Statistical and deterministic parameters for the considered variables of the RC beam

\begin{tabular}{|c|c|c|c|c|}
\hline \multicolumn{2}{|c|}{ Variable } & \multirow{2}{*}{$\frac{\text { Distribution }}{\text { Lognormal }}$} & \multirow{2}{*}{$\frac{\text { Mean }}{115 \mathrm{kN}}$} & \multirow{2}{*}{$\frac{\mathrm{COV}}{0.20}$} \\
\hline $\mathrm{P}$ & & & & \\
\hline \multirow[t]{3}{*}{$f_{c}^{\prime}$} & Poor & Normal & $37 \mathrm{MPa}$ & 0.15 \\
\hline & Fair & Normal & $53 \mathrm{MPa}$ & 0.15 \\
\hline & Good & Normal & $61 \mathrm{MPa}$ & 0.15 \\
\hline$f_{y}$ & & Normal & $600 \mathrm{MPa}$ & 0.10 \\
\hline$k_{e}$ & & Deterministic & 0.924 & \\
\hline$k_{t}$ & & Deterministic & 1 & \\
\hline$k_{c}$ & & Deterministic & 0.8 & \\
\hline \multirow[t]{3}{*}{$D_{0}$} & Poor & Normal & $1320 \mathrm{~mm}^{2} / \mathrm{yr}$ & 0.07 \\
\hline & Fair & Normal & $473 \mathrm{~mm}^{2} / \mathrm{yr}$ & 0.09 \\
\hline & Good & Normal & $316 \mathrm{~mm}^{2} / \mathrm{yr}$ & 0.10 \\
\hline$t_{0}$ & & Deterministic & 28 days & \\
\hline \multirow[t]{3}{*}{$C_{c r}$} & Poor & Normal & $0.675^{*}$ & 0.27 \\
\hline & Fair & Normal & $0.900 *$ & 0.17 \\
\hline & Good & Normal & $0.875^{*}$ & 0.16 \\
\hline \multirow[t]{2}{*}{$A_{C s}{ }^{* *}$} & Tidal & Normal & 7.758 & 0.17 \\
\hline & Atmospheric & Normal & 2.565 & 0.14 \\
\hline \multirow[t]{2}{*}{$\varepsilon_{C s} * *$} & Tidal & Normal & 0 & $\sigma=1.105$ \\
\hline & Atmospheric & Normal & 0 & $\sigma=0.405$ \\
\hline$n_{D}$ & & Determined & 0.4 & \\
\hline$\alpha$ & & Gumbel & 5.56 & 0.22 \\
\hline$i_{\text {cross }}$ & & Normal & $2 \mu \mathrm{A} / \mathrm{cm}^{2}$ & 0.10 \\
\hline
\end{tabular}

\subsection{Results}

In the firth results, this paper presents the influence of spatial variability in probability of corrosion initiation. In Figure 5 present the probability with the three cases of type material without spatial variability. It shows that influence of corrosion in structure is different when the environment is variable. We realize also that, with the same material, if structure put in Tidal environment, the corrosion is faster than 
in the Atmospheric. The influence of environment into corrosion is clear than type material. In all results later, we focus calculate the Tidal environment.

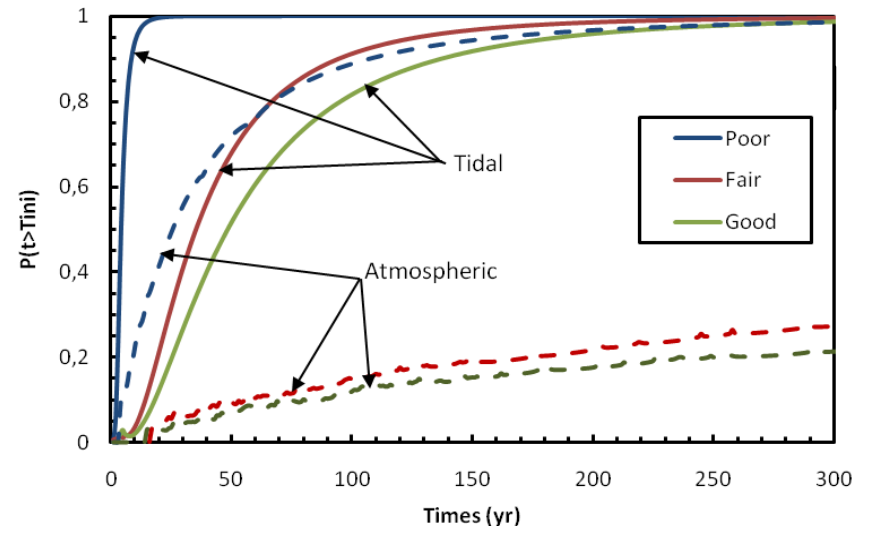

Figure 5: The cumulative distribution function of the time to corrosion initiation

Figure 6 and Figure 7 show the influence of spatial variability in the probability of corrosion initiation. With the considering the spatial variability and the correlation between elements, we realize that at the time $t$, when considering this variability, structure reaches its limit state faster than without the considering (you see in Figure 6, this factor can reach to $200 \%$ ). So, the considering in estimate reliability structure is indispensable. In results later, we will detail this influence in estimation of reliability structure of RC beam.

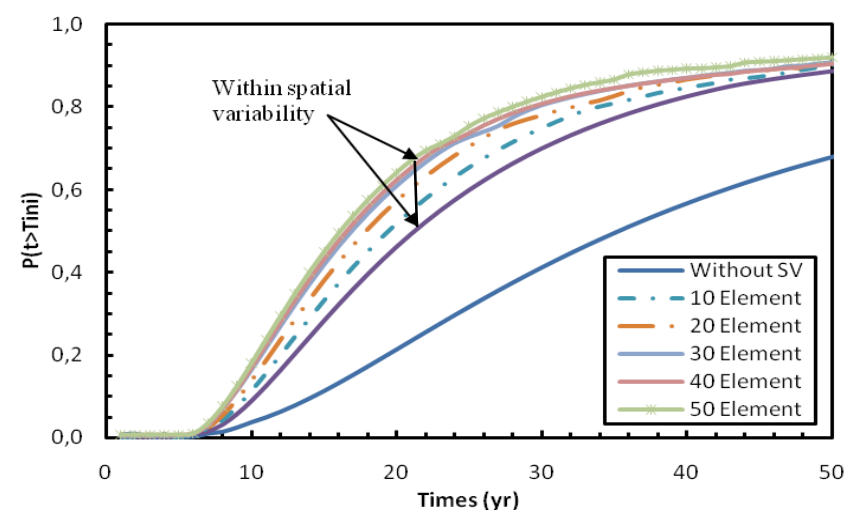

Figure 6: Influence of spatial variability in the probability of corrosion initiation (the case Fair in Tidal environment)

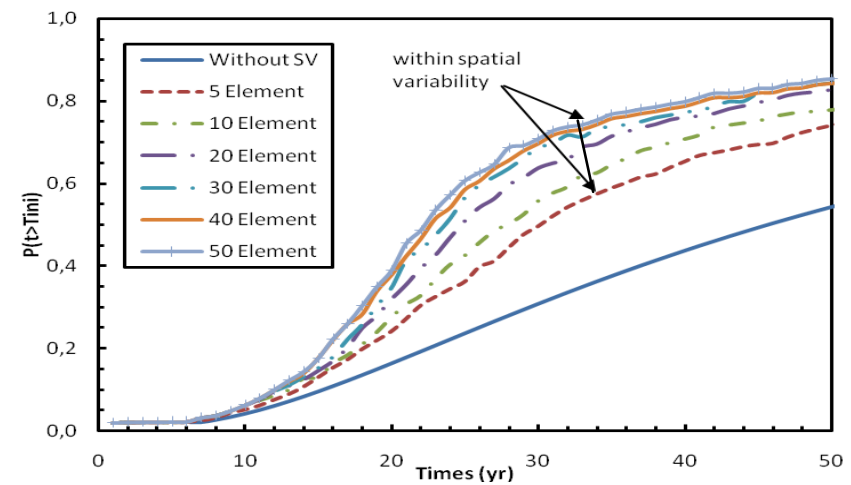

Figure 7: Influence of spatial variability in the probability of corrosion initiation (the case Good in Tidal environment)
Figure 8 and Figure 9 presents the results of probability of failure in the case with and without considering the spatial variability of the case study of Tidal environment. Based on the results, we can also realize that probability of failure obtained by considering spatial variability are higher than for the case without spatial variability.

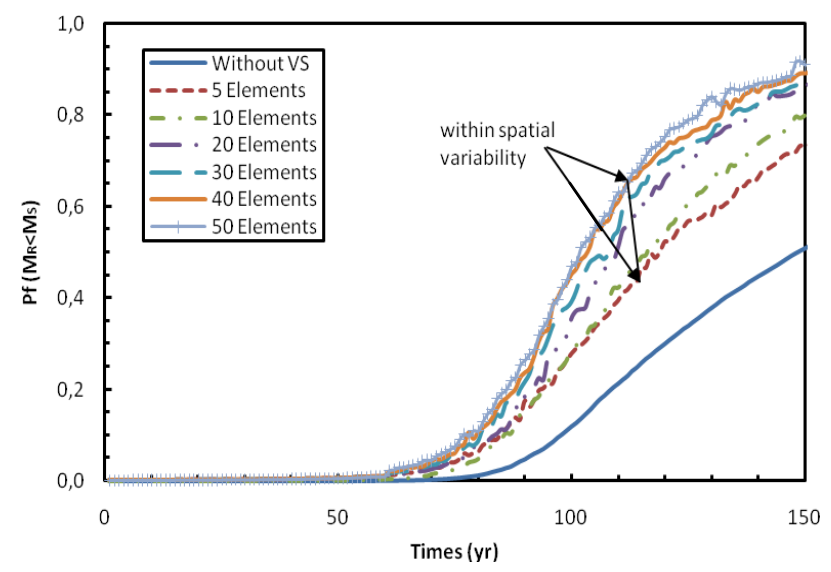

Figure 8: Influence of spatial variability in the probability of failure (the case fair in Tidal environment)

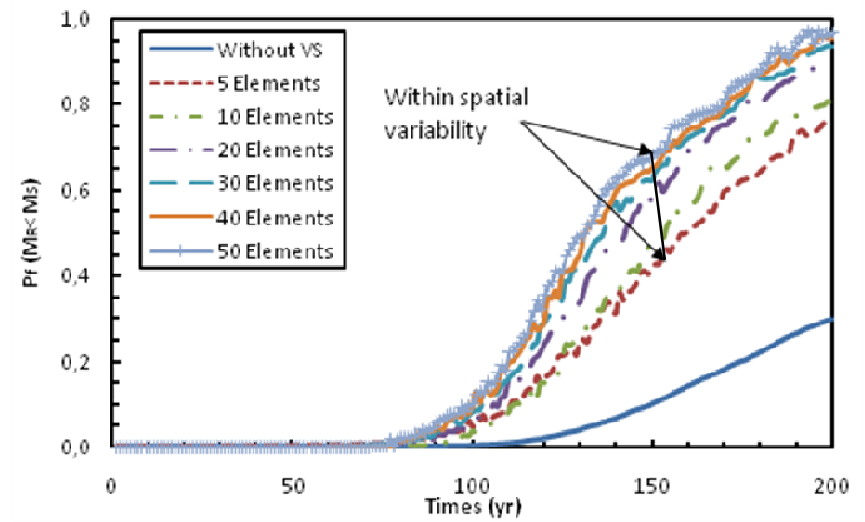

Figure 9: Influence of spatial variability in the probability of failure (the case Good in Tidal environment)

If we give a critical of probability of failure, we will obtain the result that show influence of spatial variability into the time initiation corrosion and the time reinforcement of structure. In the result later (Figure 10 and Figure 11), we present for example: $P_{f}=0.5$.

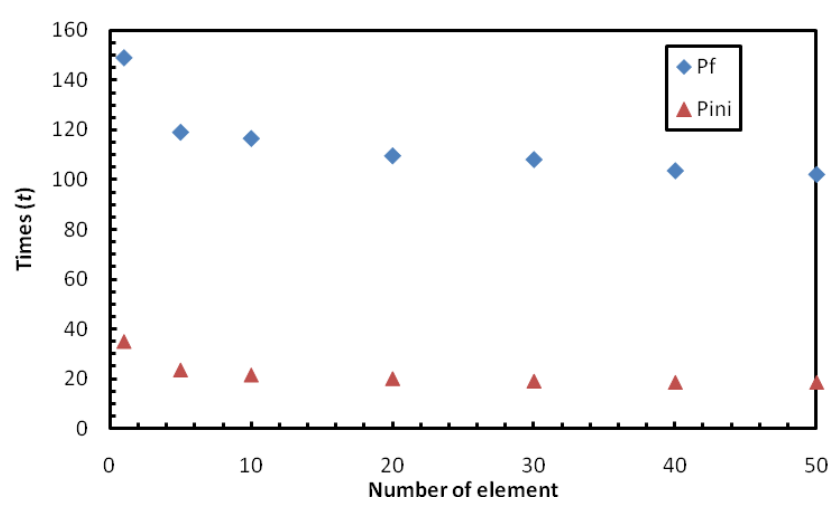

Figure 10: Estimation the times reinforced the RC beam (the case Fair in Tidal environment) 


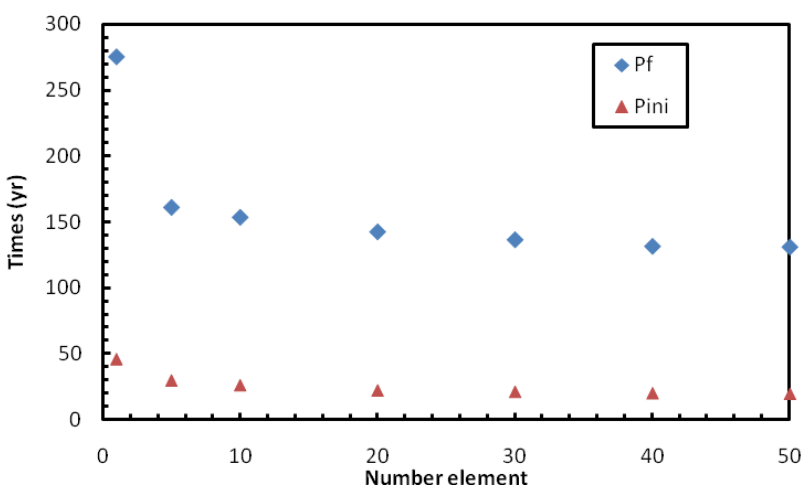

Figure 11: Estimation the times reinforced the RC beam (the case Good in Tidal environment)

It can be noted that with a critical accepted of probability of failure, the times reinforced of RC beam obtained by the considering spatial variability is smaller than for the case without the variable from 10 to $50 \%$.

\section{CONCLUSIONS}

This paper presented the model assessment probability of failure in considering spatial variability of $\mathrm{RC}$ beam. The method based on problem Binormale and FORM method in calculated the multidistribution integral. The results of the numerical example show that influence of spatial variability is very important in assessment reliability structural. The considering of spatial variability of corrosion in estimation probability of failure is indispensable. The results show that the failure probabilities within spatial variability are higher than without the variable from 10 to $50 \%$.

\section{ACKNOWLEDGEMENTS}

The authors would like to thank the ECND-PdL project (project about Condition Assessment, Monitoring and Non Destructive in the Pays de la Loire region) to support this project. Contact: Franck.Schoefs@univ-nantes.fr.

\section{REFERENCES}

Bastidas-Arteaga E, Chateauneuf A, Sánchez-Silva M, Bressolette $\mathrm{Ph}$, Schoefs F. 2010. Influence of weather and global warming in chloride ingress into concrete: a stochastic approach.Structural Safety, 32:238-249

Bastidas-Arteaga E, 2010. Probabilistic service life model of RC structures subjected to the combined effect of chloridesinduced corrosion and cycle loading. PhD thesis. University of Nantes, France.

Bastidas-Arteaga E, Chateauneuf A, Sánchez-Silva M, Bressolette $\mathrm{Ph}$, Schoefs F, 2011. A comprehensive probabilistic model of chloride ingress in unsaturated concrete. Engineering Structures, 33:720-30

Bazant Z. P., Novák D. 2000a. Probabilistic Nonlocal Theory for Quasibrittle Fracture Initiation and Size Effect. I: Theory. Journal of Engineering Mechanics. Vol. 126, No. 2, 166-174..

Bazant Z. P., Novák D. 2000b. Probabilistic Nonlocal Theory for Quasibrittle Fracture Initiation and Size Effect. II: Application. Journal of Engineering Mechanics. Vol. 126, No. 2, 175-185.

Bazant Z. P., Xi Y. 1991. Statistical Size Effect in Quasi-brittle Structures: II. Nonlocal Theory. ASCE J. of Engrg. Mech. Vol. 117, No. 11, 2623-2640.

Duracrete 2000. Statistical quantification of the variables in the limite state functions. Technical report, The European Union - Brite EuRam III - Contract BRPR-CT95-0132- Project BE95-1347/R9.

Gomes, H. M., and Awruch, A. M. 2002. Reliability of reinforced concrete structures using stochastic finite elements. Engineering Computations, 19(7-8), 764- 786.

Kenshel O.M 2009. Influence of spatial variability on whole life management of reinforced concrete. PhD Thesis, University of Dublin, Trinity College, August 2009.

Li, Y. 2004. Effect of spatial variability on maintenance and repair decisions for concrete structures. PhD thesis, Delft University, Delft, Netherlands.

Saetta, A., Scotta, R., and Vitaliani, R. 1993. Analysis of chloride diffusion into partially saturated concerte. ACI Materials Journal, 90(5):441-451.

Schoefs F, Tran TV, Bastidas-Arteaga E. Optimization of inspection and monitoring of structures in case of spatial fields of deterioration/properties. In: 11th International Conference on Applications of Statistics and Probability in Civil Engineering, ICAPS 11, Zurich, Switzerland; 2011. p. 2249-2256.

Stewart M.G., and Al-Harthy A. 2008. Pitting corrosion and structural reliability of corroding RC structures: Experimental data and probabilistic analysis. Reliability Engineering and System Safety, 93, 373-382.

Tuutti, K. 1982. Corrosion of steel in concrete. Swedish Cements and Concrete Institute.

Vanmarcke, E. 1983. Random fields: analysis and synthesis, MIT Press, Cambridge, Mass; London.

Vanmarcke, E. and Grigoriu, M. 1983. Stochastic Finite Element Analysis of Simple Beams. Journal of Engineering Mechanics, 109(5), 1203-1214.

Yuan X.-X. and Pandey M.D. 2006. Analysis of approximations for multinormale integration in system reliability computation. Structural Safety, 28, 361-377. 